\title{
Produção leiteira de ovelhas Texel submetidas a suplementação
}

\author{
Milk yeld of Texel sheeps submitted to suplementation \\ Producción lechera de ovejas Texel sometidas a suplementación
}

\section{Resumo}

A ovinocultura brasileira representa um importante segmento dentro da pecuária nacional, gerando emprego e renda ao longo da cadeia produtiva. Dentro deste segmento a produção de leite ovino ainda é incipiente no Brasil, porém apresenta grande potencial pela capacidade de agregação de valor ao produto através da produção de derivados, apreciado em mercados consumidores diferenciados. O objetivo deste estudo foi avaliar a produção leiteira de ovelhas Texel, manejadas em campo nativo recebendo suplementação. Foram utilizadas 17 ovelhas adultas, manejadas em campo nativo recebendo $1 \%$ de ração comercial contendo $14 \%$ de proteína bruta. As ovelhas foram ordenhadas em duas oportunidades dentro do período de lactação, com auxílio de ordenhadeira mecânica e administração prévia de ocitocina. O manejo nutricional permitiu manutenção do escore de condição corporal. A produção leiteira foi considerável para o padrão da raça que não representa um biótipo leiteiro. O estudo permite inferir que existe potencial para utilização da raça Texel em sistemas de produção de leite ovino.

Palavras-chave: Agroindústria; Ovinocultura; Pecuária familiar; Queijo ovino.

\begin{abstract}
Brazilian sheep farming represents an important segment within the national livestock industry, generating employment and income along the production chain. Within this segment, sheep milk production is still incipient in Brazil, but it has great potential due to the ability to add value to the product through the production of derivatives, appreciated in different consumer markets. The aim of this study was to evaluate the milk production of Texel sheep, managed in a native field and supplemented. 17 adult sheep were used, managed in a native field receiving $1 \%$ commercial feed containing $14 \%$ crude protein. The ewes were milked on two occasions during the lactation period, with the aid of a mechanical milker and prior administration of oxytocin. Nutritional management allowed the maintenance of the body condition score. Dairy production was considerable for the breed standard, which does not represent a dairy biotype. The study allows us to infer that there is potential for using the Texel breed in sheep milk production systems.
\end{abstract}

keywords: Agribusiness; Family livestock; Sheep cheese; Sheep farming. 


\begin{abstract}
Resumen
La ganadería ovina brasileña representa un segmento importante dentro de la industria ganadera nacional, generando empleo e ingresos a lo largo de la cadena productiva. Dentro de este segmento, la producción de leche de oveja es todavía incipiente en Brasil, pero tiene un gran potencial debido a la capacidad de agregar valor al producto a través de la producción de derivados, apreciados en diferentes mercados de consumo. El objetivo de este estudio fue evaluar la producción de leche de oveja Texel, manejada en un campo nativo y suplementada. Se utilizaron 17 ovejas adultas, manejadas en un campo nativo que recibieron $1 \%$ de alimento comercial que contenía $14 \%$ de proteína cruda. Las ovejas fueron ordeñadas en dos ocasiones durante el período de lactancia, con ayuda de un ordeñador mecánico y previa administración de oxitocina. El manejo nutricional permitió el mantenimiento del puntaje de condición corporal. La producción lechera fue considerable para el estándar de la raza, que no representa un biotipo lechero. El estudio nos permite inferir que existe potencial para el uso de la raza Texel en sistemas de producción de leche de oveja.
\end{abstract}

Palabras clave: Agroindústria; Ganadería familiar; Ganadería ovina; Queso de oveja.

\title{
1. Introdução
}

A produção de ovinos tem crescido no Brasil, colocando-se como mais uma alternativa à disposição do pequeno, médio ou grande produtor rural e apta para se adaptar aos diferentes sistemas de produção, desde os mais simples até aos mais tecnificados. A ovinocultura surge em regiões de boas pastagens e clima ameno, e até em condições adversas de meio ambiente, como solos pobres, rasos, com relevo acidentado e clima rude, sendo explorada principalmente pela agricultura familiar e pelas atividades formadas em moldes empresariais.

As regiões Sul e Nordeste apresentam maior participação da criação de ovinos no país. Ambas regiões apresentam diferentes aptidões produtivas: enquanto a região nordestina é destinada para a produção de carne, a região sul possui rebanho que apresenta dupla aptidão, carne e lã. Atualmente, a atividade econômica, no Rio Grande do Sul foi voltada para o setor de carne, pela desvalorização na lã nas últimas décadas. Ainda assim, existe expressivo número de produtores voltados ao mercado de lãs finas, estas sim, valorizadas.

No Brasil, os produtos de leite de ovelha têm ganhado espaço ultimamente, com cada vez maior participação nas prateleiras de frios de delicatessens e supermercados. A produção nacional é ainda muito pequena e os produtos importados aparecem como aliados na abertura do novo mercado. São produzidos no Brasil queijos tipo Feta, Roquefort, Pecorino, Boursin, amanteigados (tipo Serra da Estrela) e queijos frescos e curados de elaboração mais simples. Iogurtes firmes, batidos, integrais e desnatados também encontraram mercado receptivo e vem ganhando espaço em nichos especiais de lácteos. Apesar do pequeno volume, o leite de ovelha já é produzido em Estados do Sul, do Sudeste e do Nordeste do Brasil (Morais, 2013).

Ainda segundo Morais (2013), a exploração do leite também pode ser um complemento interessante, visto que entre cinco laticínios que beneficiam o leite de ovelha adquirido de terceiros, o preço pago varia de $\mathrm{R} \$ 2,20$ a $\mathrm{R} \$ 4,50$ o litro. Neste contexto, mesmo com o preço mínimo e uma lactação de 150 litros (ovelha de baixa produção) a receita corresponderia a um cordeiro pesado a mais por ano por ovelha. Transformado em queijo ou iogurte na propriedade essa receita poderia ser quadruplicada, mas tanto a venda do leite fluido quanto a venda de produtos beneficiados dependem de mercado comprador formado. Obviamente que junto com a receita do leite, aumentam também os custos de produção, especialmente os ligados à mão de obra.

Os sistemas produtivos de ovinos do RS não acompanharam esta mudança no produto comercializado, de lã para a carne, assim provocando déficit na eficiência produtiva. Dessa forma, o rebanho ovino no estado apresenta índice médio de desmame de cordeiro de 63\% (Guyoti, 2013), tornando o sistema produtivo desfavorável. De maneira geral, os produtores gaúchos que abandonaram a ovinocultura buscaram, ou ainda buscam a migração para outras atividades, como a agricultura. Entretanto muitos que não pretendem abandonar a atividade e estão reestruturando seus rebanhos, passando a trabalhar com 
raças de dupla aptidão (carne e lã) e com raças específicas para a produção de carne. De acordo com Ávilla et al. (2013) e Corradelo (1988), as raças de dupla aptidão, introduzidas no rebanho gaúcho, foram Texel e Corriedale.

Seguindo nesse contexto, o presente trabalho teve como objetivo avaliar a produção leiteira de ovelhas Texel, suplementadas durante o período lactacional.

\section{Materiais e Métodos}

O experimento foi conduzido no município de Santana do Livramento - RS, no campo de cooperação municipal situado na localidade da Florentina à $17 \mathrm{~km}$ do centro da cidade. O experimento compreendeu o período de março a dezembro de 2018. O solo da área experimental é do tipo Argissolo Vermelho Distrófico Abrúptico e apresenta moderada textura arenosa com relevo suavemente ondulado.

Foram utilizadas 17 ovelhas adultas da raça Texel, mantidas em sistema extensivo de pastoreio. A primeira fração do manejo alimentar executado ocorreu na forma de pastoreio horário em pastagem de aveia preta (Avena strigosa) e azevém (Lolium multiflorum) consorciado. Nesse período as ovelhas permaneceram no campo nativo sendo remanejadas diariamente para a pastagem, permanecendo duas horas. Este manejo, denominado "manejo 1" ocorreu a partir do mês de setembro, (cerca de 50 dias) e compreendeu o período em que a aveia e azevém se apresentavam em estádio vegetativo. Este manejo foi iniciado assim que as primeiras ovelhas pariram seus cordeiros, portanto fisiologicamente todos os animais estavam entre o terço final de gestação e início de lactação.

A segunda fração do manejo alimentar teve início no dia 30 de outubro, no qual as ovelhas permaneciam no campo nativo e eram racionadas diariamente com ração comercial. Esta etapa foi constituída pela adaptação das ovelhas a ingestão de ração diariamente sendo realizado em um período de 15 dias. Para tanto, no primeiro dia deste manejo todas as ovelhas foram pesadas com auxílio de balança eletrônica, e pela média de peso vivo realizou-se a suplementação diária em níveis crescentes de ração comercial contendo $14 \%$ de proteína bruta, ajustado a cada cinco dias na proporção de $0,3 \%, 0,5 \%$ e $0,7 \%$ do peso vivo, respectivamente. A terceira fração do manejo alimentar considerado iniciou no dia 14 de novembro, caracterizado pela permanência no campo nativo e suplementação com $1 \%$ do peso vivo médio do rebanho, até o término do experimento.

Realizou-se aferição do escore de condição corporal em todas as ovelhas ao início de cada manejo alimentar. O escore da condição corporal foi determinado segundo metodologia descrita por Russel et al (1969), atribuindo valores de 1 a 5 , em que 1 corresponde a animais muito magros e 5 , a animais obesos.

A primeira ordenha ocorreu no dia 20/11, uma semana após início do terceiro manejo alimentar (ração comercial fixada a $1 \%$ do peso vivo). A ordenha seguiu o modelo de Fontoura et al (2020). Assim, o protocolo de manejo pré ordenha contou a separação prévia dos cordeiros (12 horas anteriores) e aplicação de ocitocina intramuscular profunda (15 UI), cinco minutos antes do manejo da ordenha. No dia anterior a ordenha os cordeiros foram separados das ovelhas e mantidos isolados, permanecendo assim durante cinco horas. Dessa forma, permitiu-se que houvesse produção do leite no úbere. Posterior a esse período as ovelhas foram colocadas à disposição dos cordeiros para que estes esgotassem o leite produzido no período. Após a mamada, as ovelhas foram separadas novamente dos cordeiros, as 20:00, para que assim permanecessem até a ordenha que seria realizada no dia seguinte.

A ordenha foi realizada na manhã seguinte, realizada por ordenhadeira mecânica em uma plataforma adaptada que permitia a alocação de quatro ovelhas por lote.

Após a ordenha o leite de cada ovelha foi pesado individualmente em balança de precisão, e uma amostra de $40 \mathrm{~mL}$ foi coletada e enviada ao laboratório de qualidade do leite da Embrapa Clima Temperado em Pelotas-RS, para análise da composição química e contagem de células somáticas (CCS). A ordenha iniciou as 11:00 da manhã do dia, cerca de 15 horas 
após a separação dos cordeiros. Uma segunda ordenha foi realizada no dia $05 / 12$, seguindo o mesmo protocolo da primeira ordenha. O cálculo da produção leiteira diária foi dado pela fórmula:

$$
\text { PL ajustada a } 24 \text { horas }=\text { PL observada } * 24
$$

A partir da obtenção destas mensurações calculou-se a média obtida entre os dois momentos.

\section{Resultados e Discussão}

De acordo com Siqueira (1996), a condição corporal das ovelhas na fase pós-parto afeta diretamente a produção de leite, e consequentemente, o desenvolvimento dos cordeiros. Rabassa et al (2009) ressaltaram a modificação no perfil metabólico de ovelhas em distintas condições corporais, destacando déficit proteico e energético de ovelhas que apresentam acentuada perda de peso. Neste sentido, a expressão do potencial leiteiro e mesmo a manutenção da produção leiteira depende do status nutricional do rebanho, que tende a sofrer grande variação após o parto, especialmente em sistemas baseados em campo nativo (Menezes et al, 2017).

Na Tabela 1 pode-se observar que o peso corporal obtido ao início da segunda fração do manejo alimentar, bem como o escore de condição corporal médio durante todo o experimento, mensurado ao início de cada protocolo alimentar.

Tabela 1 - Tabela demonstrativa de escore condição corporal das ovelhas ao início de cada fase alimentar.

\begin{tabular}{lcccc}
\hline & PC $($ KG $)$ & ECC 1 & ECC 2 & ECC 3 \\
\hline MÉDIAS & 59,6 & 2,44 & 2,5 & 2,5 \\
DESVIO PADRÃO & $\pm 5,8$ & $\pm 0,4$ & $\pm 0,6$ & $\pm 0,5$ \\
\hline
\end{tabular}

PC = Peso corporal ECC = Medições de escore condição corporal em 3 momentos distintos. Fonte: Autores.

Em relação ao escore condição corporal (ECC) das ovelhas (Tabela 1), não foi constatada a redução no pós-parto, divergindo dos resultados encontrados por Pires et al. (2000) que afirmam que neste período de aleitamento as ovelhas reduzem seu peso corporal em cerca de 5,33\% de seu peso vivo. Ademais, resultados encontrados por Susin (1996), apontam que ovelhas mantidas em campo nativo apresentam perda de peso ainda maior nesta fase, dessa forma, dificultando o manejo de preparo corporal para a próxima gestação. Neste sentido, pode-se concluir que o manejo proposto foi eficiente no que diz respeito a manutenção das exigências nutricionais requeridas pela lactação.

Na Tabela 2 é possível observar as médias obtidas através dos métodos utilizados no experimento para quantificação produtiva de leite, produção de leite ajustada para $24 \mathrm{~h}$ e dias de lactação.

Tabela 2 - Tabela demonstrativa de produção leiteira, produção leiteira ajustada para 24h e dias de lactação.

\begin{tabular}{lccc}
\hline & PL $(\mathbf{m L})$ & PLA $(\mathbf{m L})$ & DL \\
\hline MÉDIA & 736,6 & $1.203,8$ & 52 \\
DESVIO PADRÃO & $\pm 292,9$ & $\pm 473,7$ & $\pm 18,5$ \\
\hline
\end{tabular}

PL = Produção leiteira estimada em mL; PLA = Produção leiteira ajustada em um período de 24h; DL = Dias em lactação. Fonte: Autores. 
A produção leiteira $(\mathrm{PL})$ das ovelhas apresentou média expressiva, embora a raça Texel não seja considerada de aptidão leiteira. Os resultados indicam que as ovelhas produziram em média 732,6 mL durante um período de 15 horas. Quando esse período foi ajustado para 24 horas a produção das ovelhas apresentou média de 1.203,84 mL de leite, mostrandose próximo aos resultados encontrados por Zeppenfeld et al. (2007), que estudando a produção e composição do leite ovino durante as sete primeiras semanas de lactação, encontraram resultados de $1.430 \mathrm{~mL} /$ dia de produção leiteira em ovelhas Texel. Fontoura et al (2020) estudando as características da lactação na mesma raça, encontraram a maior produção leiteira entre os 45 e 60 dias de lactação, relatado média de $0,816 \mathrm{~kg}$.

A média em dias de lactação (DL) mensurada durante o período de início da produção de leite das ovelhas até o dia da primeira ordenha, foi de 52 dias, levando em conta que as ovelhas com maior e menor tempo de lactação apresentavam 75 e 24 dias pós-parto, respectivamente. Segundo resultados encontrados por Roda et al. (1987), em estudos avaliando a produção, composição e características físico-químicas de leite ovino, constataram que ovelhas da raça Corriedale atingiram o pico de lactação aos 35 dias pós-parto e a produção máxima de leite foi de 1,49 Kg/dia.

Em relação a composição química do leite, existe grande variação em função de diversas fontes de variação. Souza et al. (2005), citam como influência fatores como: raça, estagio de lactação, variação durante a ordenha, condições climáticas, alimentação, entre outros.

Na Tabela 3, pode-se observar a média obtida para cada variável analisada da composição química do leite ovino e em seguida seu respectivo desvio padrão.

Tabela 3 - Composição química do leite de ovelhas Texel manejadas em campo nativo com suplementação.

\section{COMPOSIÇÃO QUIMICA DO LEITE}

\begin{tabular}{lccccc}
\hline & $\begin{array}{c}\text { GORDURA } \\
(\boldsymbol{\%})\end{array}$ & $\begin{array}{c}\text { PROTEÍNA } \\
(\boldsymbol{\%})\end{array}$ & $\begin{array}{c}\text { LACTOSE } \\
(\boldsymbol{\%})\end{array}$ & $\begin{array}{c}\text { SÓLIDOS } \\
(\boldsymbol{\%})\end{array}$ & $\begin{array}{c}\text { CCS } \\
(\mathbf{X ~ 1 0 0 0 )})\end{array}$ \\
\hline MÉDIA & 3,70 & 4,43 & 4,16 & 13,29 & 2044,35 \\
DESVIO PADRÃO & 1,03 & 0,70 & 0,87 & 1,49 & 2315,13 \\
\hline
\end{tabular}

Fonte: Autores.

O teor de gordura no leite apresentou em média 3,7\% g/100g de leite. Brito et al. (2005), desenvolveram estudos avaliando a composição química do leite em ovelhas da raça Lacaune, encontrando um teor médio de gordura de 4,46\%. Luquet (1991), descreveu que ocorre aumento progressivo nos valores encontrados para quantificar a presença da gordura no leite conforme o avanço do período de lactação. Bencini e Pulina (1997), afirmaram que existe correlação negativa entre a produção e a gordura do leite ovino, ou seja, ovelhas que produzem maior quantidade de leite, a gordura diminui. Fontoura et al. (2018) obtiveram em ovelhas Texel taxa média de 5,48\% de gordura, mensuradas em três momentos distintos da lactação. Neste sentido, pode inferir que as ovelhas ordenhadas neste primeiro momento apresentavam-se no pico da lactação, a julgar pela produção obtida, data média de parto e percentual de gordura.

Os teores de proteína encontrados na análise do leite apresentaram média de 4,43\% g/100g de leite com um desvio padrão de $\pm 0,70 \mathrm{~g} / 100 \mathrm{~g}$. Este resultado mostrou-se semelhante ao encontrado por Scholz (1997). Em estudos comparando o leite ovino com caprino e bovino. Morais (2013), encontrou resultados mostrando que o leite ovino possui maior teor de proteína em sua composição quando comparado aos leites de vaca e cabra. 
A média de lactose encontrada no leite foi de 4,16\% com desvio padrão de $\pm 0,87$. O maior teor foi encontrado em ovelhas com mais de 60 dias em lactação, ou seja, e ovelhas que estavam no pico de lactação como no presente estudo, coincidindo com Brito et al. (2006), que também obteve os maiores teores de lactose em ovelhas que já haviam atingido o pico de produção. Cordero et al. (2002), afirmam que a porcentagem de lactose (elemento solúvel mais abundante no leite) está diretamente ligada a quantidade de leite produzido, ou seja, a lactose apresenta atividade osmótica maior que os outros elementos, assim, caracterizando maior quantidade na produção leiteira.

Maisi (1990), determina que os métodos mais utilizados para a detecção de mastite subclínica são a contagem de células somáticas e a constatação da presença de patógeno no leite. Kalantzopoulos et al. (2004), afirmou que a contagem das células somáticas é extremamente utilizada para avaliar a qualidade do leite e definir o seu preço. No presente trabalho o teor de células somáticas médio encontrado foi de 2.044.350 superior ao resultado encontrado por Brito et al. (2006). Segundo Gonzalo et al. (1994), pesquisando composição do leite em ovelhas Churras na Espanha, ao início e final de lactação ocorre um aumento fisiológico na quantidade de células somáticas. Entretanto, cabe salientar que no Brasil não existem referencias ou mesmo legislação que aponte para um número máximo de células somáticas por mL de leite ovino.

\section{Considerações Finais}

A raça Texel apresenta uma boa performance para a aptidão leiteira, podendo-se utilizar este potencial como uma diversificação na produção dos pecuaristas familiares que buscam por alternativas mais rentáveis.

Os manejos alimentares utilizados obtiveram resultados satisfatórios na manutenção das ovelhas, possibilitando pouca variação de escore condição corporal. Mais estudos que incluam seleção para produção leiteira, intensificação nutricional e cruzamento com raças especializadas na produção de leite devem ser realizados.

\section{Agradecimentos}

Os autores agradecem o auxílio financeiro da FAPERGS e UERGS, através das bolsas de pesquisa.

\section{Referências}

Ávila, V. S., Fruet, A. P. B., Barbieri, M., Bianchini, N. H. \& Dörr, A. C. 2013. O retorno da ovinocultura ao cenário produtivo do Rio Grande do Sul. Revista Eletrônica em Gestão, Educação e Tecnologia Ambiental, Santa Maria, 11(11), 2419-2426. https://doi.org/10.5902/22361170.

Bencini, R. \& Puliuna, G. 1997. The quality of sheep milk: a review. Australian Journal of Experimental Agriculture. 45, 182 220. https://doi.org/10.1071/EA96014

Brito, M. A., González, F. D., Ribeiro, L. A., Campos, R., Lacerda, L., Barbosa, P. R. \& Bergmann, G. 2006. Composição do sangue e do leite em ovinos leiteiros do sul do Brasil: variações na gestação e na lactação. Ciência Rural, Santa Maria, 36(3), 942-948. https://doi.org/10.1590/S010384782006000300033

Corradello, E. F. A. 1988. Criação de ovinos: antiga e contínua atividade lucrativa. São Paulo: Ícone. 124 p.

Doney, J. M., Peart, J. N, Smith, W. F. \& Louda, F.. 1979. A consideration of the techniques for estimation of milk yeld by suckled sheep and a comparision of estimates obtained by two methods in relation to the breed, level of production and stage of lactation. Journal of Agricultural Science, 92(1), 123-132. https://doi.org/10.1017/S0021859600060573

Fontoura, E. A. B, Rodrigues, D. P., Damilano, A. S, Perez, H. S.A, Rosa, R. S, Tâmara, J. Q., Gomes, A. F.F., Corrêa, G. F. \& Menezes, L. M. 2018. Composição química do leite de ovelhas Texel criadas extensivamente. VI Congreso Aupa - Asociación Uruguaya De Producción Animal. Tacuarembó, Uruguay.1, 25 .

Fontoura, E. A. B, Tâmara, J. Q., Rodrigues, D. P., Maydana, G. M., Santos, R. M. L., Munhoz, M. L., Corrêa, G. F. \& Menezes, L. Características da lactação de ovelhas Texel criadas extensivamente. Brazilian Journal of Development., Curitiba, 6(1),1586-1597. https://doi.org/10.34117/bjdv6n1-109

Gonzalo, C., Carriedo, J. A., Baro, J. A. \& San Primitivo, F. Factors influencing variation of test day milk yield, somatic cell count, fat and protein in dairy sheep. Journal of Dairy Science, 77, 1537-1542. https://doi.org/10.3168/jds.S0022-0302(94)77094-6.

Guyoti, V. M. Efeito da esquila durante a gestação no metabolismo de ovelhas e cordeiros na fase pós nascimento. 2013.76 f. Dissertação (Mestrado em ciências veterinárias) - Faculdade de veterinária. Programa de pós-graduação e ciências veterinárias, Porto Alegre. 
Research, Society and Development, v. 10, n. 2, e30010212500, 2021

(CC BY 4.0) | ISSN 2525-3409 | DOI: http://dx.doi.org/10.33448/rsd-v10i2.12500

Kalantzopoulos, G., Dubeuf, J. P., Vallerand, F., Piris, A., Casalta, E., Lauret, A. \& Trujillo, A. Characteristics of sheep and goat milks: quality and hygienic factors for the sheep and goat dairy sectors. Bulletin-International Dairy Federation, 390, 17-24, 2004. https://hal.inrae.fr/hal-02672240

Luquet, F.M. La leche: de la mama a la lechería. Zaragoza: Acribia, 1991. 195p.

Maisi, P. Milk NAGase, CMT and antitrypsin as indicators of caprine subclinical mastitis infections. Small Ruminant Research, 3, 493- 501. https://doi.org/10.1016/0921-4488(90)90080-P

Menezes, L. M., Fontoura, E. A. B., Damilano, A. S., Rosa, R. S., Perez, H. A., Gomes, A. F. F., Cunha, P. T., Chagas, R. A., Corrêa, G. F. Desempenho de cordeiros Texel e Corriedale mantidos em azevém em fim de ciclo. Revista electrónica de Veterinaria. 18(12):1-9. 2017. https://doi.org/10.34117/bjdv6n1-353

Morais, O. R. de. Produção de leite de ovelhas no Brasil. 2013. In: 4. Simpósio Internacional De Bovinocultura Leiteira. Viçosa, MG: UFV. $317-324$.

Pires, C. C., Silva, L. F., Farinatti, L, H. E., Peixoto, L. A. O., Fübner, M. C. \& Cunha, M. A. Crescimento de cordeiros abatidos com diferentes pesos. 2. Constituintes corporais. Ciência Rural, Santa Maria, 30(5), 869-873, 2000. https://doi.org/10.1590/S0103-84782000000500022

Rabassa, V. R., Tabeleão, V. C., Schneider, A., Menezes, L. M., Schossler, E., Severo, N., Schwegler, E., Goulart, M. A., Del Pino, F. A. B., Nogueira, C. E. W. \& Corrêa, M. N. 2009. Avaliação metabólica de ovelhas de cria mantidas em campo nativo durante o período de outono/inverno. Revista Brasileira de Agrociência, 15(1-4), 125-128. https://doi.org/ 10.18539/cast.v15i1-4.1999

Ribeiro, E. L. A., Mizubuti, I. Y., Rocha, M. A., Silva, L. D. F., Bergamo, H., Mori, R. M., Podleskis. M. R. \& Ferreira, D. L. 2004. Uso da ocitocina na estimativa de produção e composição do leite de ovelhas Hampshire Down. Revista Brasileira de Zootecnia, 33(6), 1833-1838. https://doi.org/10.1590/S151635982004000700022

Roda, D. S., Dupas, W., Santos, L. E., Feitoza, A. S. L.\& Bianchine, D. 1987. Produção de leite de ovelhas Ideal e Corriedale e desenvolvimento do cordeiro. Boletim de Indústria Animal, Nova Odessa, SP, 44(2), 297-307. http://www.iz.sp.gov.br/pdfsbia/1379440677.pdf

Russel, A. J. F., Doney, J. M., Gunn, R. G. Subjective assessment of body fat in live sheep. Journal of Agricultural Science, 72, $451-454$. https://doi.org/10.1017/S0021859600024874

Scholz, W. 1997. Elaboración de quesos de oveja y de cabra. Zaragoza: Acribia, 145p.

Siqueira, E. R. Recria e terminação de cordeiros em confinamento. In: Silva Sobrinho, A. G., Batista, A. M. V., Ortolani, E. L. 1996. (Eds.). Nutrição de ovinos. Jaboticabal: FUNEP, 175-212.

Souza, A. C. K., Osório, M. T., Osório, J. C. S., Oliveira, N. M., Vaz, C. M. S., Souza, M., Corrêa, G. F. Produção, composição química e características físicas do leite de ovinos da Raça Corriedale. Revista Brasileira de Agrociência, 11(1), 73 -77.

https://doi.org/ 10.18539/cast.v11i1.1173

Susin, I. 1996. Exigências nutricionais de ovinos e estratégias de alimentação. In: Silva Sobrinho, A. G. et al. (Eds.). Nutrição de ovinos. Jaboticabal: FUNEP. p. 119-141.

Zeppenfeld, C. C., Pires, C. C., Muller, L., Cunha, M. A., Carvalho, S., \& Bandeira, A. H. 2007. Produção e composição do leite ovino durante as sete primeiras semanas de lactação. Zootecnia Tropical, 25(2), 77-81. http://ve.scielo.org/scielo.php?script=sci_arttext\&pid=S0798-72692007000200003 